\title{
Parental age and the risk of depression: a nationwide population-based study
}

Svetlana Filatova*, S Upadhyaya, T Luntamo, A Sourander, R Chudal

${ }^{*}$ Research Centre for Child Psychiatry Research, University of Turku, Finland

\section{Background}

Parental age has been associated with several psychiatric disorders such as schizophrenia, autism and bipolar disorder in the offspring. However, the association between parental age and depression has not been studied extensively and findings from three previous register-based studies are inconclusive.

\section{Aims}

The aim of this study was to explore an association between parental age and depression in the offspring.

\section{Methods}

The cases (ICD-9 code 2961 and ICD10 codes $F 32$ and $F 33, n=37,682$ ) were obtained from the Finnish register for Health Care. Controls were matched 1:4 $(n=148,795)$ to the cases by gender and the date of birth. Paternal age was categorized to eight categories from $<20$ to $\geq 50$ years. Maternal age had the same categories except the oldest age category was $\geq 40$ years. Conditional logistic regression was used to examine the associations. The associations were adjusted for age of other parent, maternal depression, parental psychiatric history, maternal SES, place of residence, marital status, maternal smoking during pregnancy, number of previous births, and birth weight.

\section{Results}

Fathers and mothers aged $<20$ years had 1.6 fold (OR 1.56 95\% Cl 1.32-1.84) and 1.7-fold (OR 1.72, 95\% $\mathrm{Cl} 1.56-1.90$ ) increased risk of having an offspring with depression as compared to the 25-29-year-old parents. Similarly, fathers aged $\geq 50$ years and mothers aged $\geq 40$ had 1.7 -fold (OR 1.72, 95\% Cl 1.43-2.07), and 1.2-fold (OR 1.22, 95\% Cl 1.10-1.35) increased risk respectively (Table 1 ).

Table 1. Parental age and risk of diagnosed depression in Finland 1995-2012

\begin{tabular}{|c|c|c|c|}
\hline $\begin{array}{l}\text { Paternal age and risk of } \\
\text { depression }\end{array}$ & $\begin{array}{c}\text { Cases } \\
\text { (n=37,682) } \\
n, \%\end{array}$ & $\begin{array}{c}\text { Controls } \\
\text { (n=148,795) } \\
n, \%\end{array}$ & OR $(95 \% \mathrm{Cl})^{\mathrm{c}}$ \\
\hline \multicolumn{4}{|l|}{ Paternal age groups, years } \\
\hline$<20$ & $504(1.3)$ & $949(0.6)$ & $1.56(1.32-1.84)^{\star}$ \\
\hline $20-24$ & 4997 (13.3) & $14580(9.8)$ & $1.22(1.15-1.29)^{\star}$ \\
\hline 25-29 (Reference) & $11161(29.6)$ & $46185(31.0)$ & 1 \\
\hline $30-34$ & 10807 (28.7) & $48374(32.5)$ & $1.00(0.96-1.04)$ \\
\hline $35-39$ & 657 (16.1) & $25151(16.9)$ & $1.10(1.04-1.16)^{\star}$ \\
\hline $40-44$ & $2417(6.4)$ & $8882(6.0)$ & $1.26(1.17-1.36)^{\star}$ \\
\hline $45-49$ & $723(1.9)$ & $2402(1.6)$ & $1.43(1.25-1.60)^{*}$ \\
\hline$\geq 50$ & $286(0.8)$ & $787(0.5)$ & $1.72(1.43-2.07)^{\star}$ \\
\hline
\end{tabular}

Maternal age and risk of depression $^{b}$

Maternal age groups, years $<20$

20-24

25-29 (Reference)

30-34

35-39

$\geq 40$

$\begin{array}{ccc}1836(4.9) & 3836(2.6) & 1.72(1.56-1.90)^{\star} \\ 8346(22.1) & 26472(17.8) & 1.29(1.23-1.36)^{\star} \\ 12562(33.3) & 55343(37.2) & 1 \\ 9555(24.4) & 42142(28.3) & 0.97(0.93-1.01) \\ 4280(11.4) & 17186(11.6) & 1.04(0.98-1.10) \\ 1102(2.9) & 3804(2.6) & 1.22(1.10-1.35)^{\star}\end{array}$

a: 730 observations missing in cases and 1485 in controls; b: one observation missing in cases and 12 in controls, ${ }^{*}$ statistically significant $(p<0.05)$; : adjusted for age of other parent, maternal depression, parental psychiatric history, maternal SES, place of residence, marital status, maternal smoking during pregnancy, number of previous births, and birth weight

\section{Conclusions}

The findings of this study are in line with previous research showing an association of parental age with psychiatric disorders in offspring. These results should be taken in consideration by health professionals to improve early detection and treatment, and when developing preventive strategies. 